\title{
Linking Homework to Achievement in Mathematics: An Examination of 8th Grade Arab Participation in TIMSS 2015
}

\author{
Faisal Abdelfattah \\ Assoc. Prof., Imam Abdulrahman Bin Faisal University, Saudi Arabia, \\ faabdelfattah@iau.edu.sa
}

\author{
Jasmine Lam \\ Temple University, USA, jasmine.lam@temple.edu
}

\begin{abstract}
Homework is generally one factor that has been discussed and claimed to have a relationship with achievement; it has a central role in providing students with opportunities to continue learning out of the school. This study forms one of crosscultural investigations that analyze the links between homework variables and achievement in mathematics. Data was drawn from TIMSS database 2015, including 477 schools and 73,987 eighth grade students from 10 Arab countries. Analysis showed that the majority of Arab students spend less time doing homework (less than 60 minutes) and do not need to take homework every day to strengthen their knowledge and get better scores in mathematics. Two-level analyses revealed that different associations were seen in most of Arab countries between homework time, homework frequency, computer use, and internet use in doing homework with achievement in mathematics. The result was interpreted in terms of the consistency between instruction and homework evaluation.
\end{abstract}

Keywords: cross-cultural, homework, mathematics, achievement, two-level modeling

\section{INTRODUCTION}

Students' progress in mathematics has consequences on country's growth around the globe (Baker \& LeTendre, 2005; Phan et al., 2010) through preparing students with quantitative skills and raising stronger foundations to skills for lifelong learning. Mathematics provides useful tools that enable students to understand science, technology, and engineering. As a result, mathematics achievement becomes a central source of information (Schleicher, 2002) and has commonly shared interest among educators, parents and others involved in making decisions about students' academic achievement.

Clearly, obvious efforts were taken to understand mathematics achievement and identifying the contextual factors across educational systems that contribute to high

Citation: Abdelfattah, F., \& Lam, J. (2018). Linking Homework to Achievement in Mathematics: An Examination of 8th Grade Arab Participation in TIMSS 2015. International Journal of Instruction, 11(4), 607-624. https://doi.org/10.12973/iji.2018.11438a 
achievement and understand how factors enhance or limit the achievement of different groups of students (Son, Han, Kang, \& Kwon 2016). Continuing these efforts, the present investigation is based on large-scale data from the Third International Mathematics and Science Study (TIMSS) to identify student and teacher characteristics related to homework influencing mathematics achievement within particular countries. Very little research was done on Arab students' results participating in TIMSS. Findings from this research have important implications for policy makers concerning the improvement of mathematics achievement.

Phan et al. (2010) encouraged researchers to focus on developing countries and those of poor performance in international studies in contrast to few developed countries and high achievers. Consequently, developing and low achievers can base their educational decisions on findings from their own students (Riddell, 1997) instead of implementing models that was generated from developed counties. Dissimilarity of attributes between developing and developed countries could form a bias in understanding findings in achievement.

\section{Context and review of literature}

Contextual factors that possibly improve mathematics achievement were investigated in many studies, but their findings appeared to be inconsistent. For example, family related factors and school related factors differ in their relationship with achievement (Horsley \& Walker, 2013; Carmichael \& MacDonald, 2014; Power et al., 2007).

Homework is one factor that has been discussed and claimed to have a relationship with achievement (Cooper, Lindsay, \& Nye, 2000; Rodriguez, 2004; Trautwein, 2007, Dettmers, Trautwein, \& Ludtke, 2009). Parental involvement and homework were related to student achievement in schools (Cooper, Harris, \& Nye, 2000).

Most teachers perceive homework as valuable educational tool; therefore, they assign tasks to students studying mathematics to achieve one of the course objectives that deal with developing creativity, problem solving and encouraging critical thinking (Kandemir \& Gür , 2009) all through homework activities given to them out of the class period; which has a central role in providing opportunities to continue learning out of the school.

Homework becomes more effective and enjoyable experience to students when it is planned well (Ekici, 2014). It is an important variable associated with student performance in school. Authors introduced frequency of homework and time spent on homework into discussion (Dettmers, Trautwein, \& Ludtke, 2009; Murillo \& MartinezGarrido, 2014, Warton, 2011; Valle et al., 2016) to explain the association between homework and achievement gains. To add more details to this, time and quantity found to be significantly linked when studying homework styles.

Cooper et al. (2012) defined homework as any task related to academic that is assigned by teachers to be done by students outside the instructional time. According to this definition, homework can be used to ensure readiness for the following classes; strengthen student understanding; and improve the obtained skills. Homework is an 
occasion that improves the student's feeling of responsibility, study independently, and self- regulation (Ekici, 2014). As a consequence, students develop their study habits effectively and can show that learning can take place at home as well as school. Students may get the high efficiency from homework when he or she is capable to accomplish the homework successfully (Ekici, 2014), receives feedback, and perceive it in a way appropriate for the subject introduced in the classroom.

Lamb and Fullarton (2000) using TIMSS database concluded that, in Australia, although student characteristics influence differences in achievement in mathematics, classroom and school factors also contribute considerably. Constantly, In 2001 Lamb and Fullarton compared US and Australia using TIMSS database, the results revealed about one-third of achievement variation in the US was accounted by classroom factors and about onequarter in Australia, suggesting the impact of compositional and organizational variables of the classroom. The results have important implications on the improvement of achievement in mathematics.

Teachers' factors do matter, In the US; teachers of more experience enhance higher levels of achievement. Also, their method on homework, measured by the time amount they locate for homework, has effect on achievement after controlling for other factors (Lamb \& Fullarton, 2001).

Dettmers, Trautwein, and Ludtke (2009) conducted a cross-cultural comparison analyzing 2003 cycle data which obtained from 231,759 students in 40 countries participated in the Programme for International Student Assessment (PISA). Findings of the two-level analyses showed a significant positive relationship between the students' scores in mathematics and the amount of time spent doing the homework at the group level, but no clear relationship at the student level across the countries. The association was decreased significantly after controlling other school and students' background. In most countries at the student level, Dettmers, Trautwein, and Ludtke found an opposite negative relationship between homework time and achievement in mathematics, which indicates that when students spend less time on mathematics homework than their colleagues in the class they tend to get higher scores on mathematics test.

Mikk (2006) revealed that there was a relationship between mathematics scores obtained from TIMSS 2003 and teachers' styles of assigning homework, also more exercises were effective in elevating achievement.

Murillo and Martinez-Garrid (2014) claimed that homework must be integrated in lesson routines by using the knowledge and skills accumulated through homework during the next lessons. If teachers want to increase the amount of homework, they are advised to do so when homework is used to teach new concepts. Authors recommend the duration must not exceed half an hour a day in Latin America primary schools.

Another direction of researching homework focusing on parent's involvement while their kids are solving the homework (Cooper, Lindsay, \& Nye, 2000; Falch \& Rønning, 2011, Rudman, 2014; Margolis, 2015), Rudman (2014) brings out the need to understand the student's motivation and parent's involvement to consider proper 
approaches that meet kids expectations. Also, studies have examined another aspects regarding homework, e.g. getting help for doing homework through phone calls (Reach \& Cooper, 2004) or online homework (Rochelle, Feng, \& Murphy, \& Mason, 2016). Evidences showed an increase in students' performance when they use paper type for homework. This supports the teachers' practices and explains why they still use this method (Spătărelu, 2017).

Valle, et al. (2016) found a positive relationship between school achievement and the homework quantity, time management being related to homework quantity, type of approaching homework being related to time management. Other researchers connected homework quantity to characteristics such as family's socio-economic level; motivation to learn (Rønning, 2010; Dettmers, Trautwein, \& Ludke, 2009) and parent's involvement while doing homework (Farrell \& Danby, 2013; Margolis, 2015).

Rudman (2014) claimed over the fact that homework is not investigated sufficiently. He brings attention to the need for more research to understand the roles of different variables to homework. Dissimilar opinions at the international level and the variables effect homework emerged according to the country where the study is conducted in.

Although homework has been a focus of research for many years, the strength of its relationship with achievement is not yet fully clear. A number of studies have generated contradicting findings; significant, insignificant, positive, and negative effects of homework on achievement, studies showed that homework increases students' scores (Cooper, Robinson, \& Patall, 2006; Rowell \& Hong, 2002; Cheema \& Sheridan, 2015). Mau and Lynn (2000) used data of 20,612 tenth grade students obtained from the American National Educational Longitudinal Study (NELS) to study the link between weekly hours doing out of school homework and achievement. Mau and Lynn noted higher mean scores for males on mathematics and science tests. Female students reported doing more homework out of school than male students and higher positive correlations were consistently found for females than for males when the amount of time for doing homework is associated with test scores. The results could suggest that homework is an essential contributor to achievement for female students compared with their counterpart of males.

Kitsantas, Cheema, and Ware (2011) used the US sample involved in a national survey, 5,200 high schools students, and the findings showed a negative significant correlation but weak coefficient that exists between time spent on doing homework and achievement in mathematics. Males and females did not differ significantly in terms of the relationship between time spent on homework and achievement.

Students believe that technology facilities and internet can enhance learning from homework and let them experience a great pleasure. Researchers (Dodson, 2014; Hopkins, 2005; Bafile, 2005) perceived technology use as one of the factors that increases students' motivation and raises their achievement while doing homework. Salend et al. (2004) pointed out that teachers use websites to support the understanding of homeworks, e.g. list of assignments, assessment rubrics, facilitate creating group work, provide access to extra information, and provide opportunity to raise any problem 
they face online. The Information and Communication Technology (ICT) based instruction varies across educational Arab systems, especially in terms of the level of access in schools and usage outside the schools. Computers are dedicated to assist instruction in classrooms and in some cases for administrative purposes. However, studies show that some Arab countries are still lag behind in utilizing ICT in their education systems (Wiseman, Abdelfattah, \& Almassaad, 2016).

According to Ekici (2014), students must be provided with opportunities to locate resources such as library, internet, references and further sources that belong to the subject. Cooper et al. in 2006 categorized types of studies that were conducted to explore the effects of homework on achievement into three types. One type which used experimental designs found positive effects of homework; the second type which used data from cross-sectional studies or high-school database found positive significant associations when controlling confounding variables; the third type which used bivariate correlation coefficient between homework and performance found that most correlations were positive. Cooper et al. noted design flaws in some of those studies investigated the relationship between homework and achievement.

Examining the previous literature shows the importance of ongoing research in mathematics achievement to explore ways geared to improve performance across countries. Also, Dettmers, Trautwein, and Ludtke (2009) argued that some evidences concerning the homework- achievement relationship may differ across countries. The advancement in educational research field enables researchers to illuminate new ideas to improve educational systems from theoretical and methodological perspective as well. Also, sharing ideas and learning from others build a rich opportunity for educators to advance education in their countries.

The educational settings in Arab countries are single-sex classrooms where male and female students are separated in schools and their teachers are from the same sex. Furthermore, differences of socialization process in school and family led Arab boys to be less critical about them and have led to higher self-concept more than expected in terms of achieving their objectives, encouraging competition, and over emphasizing marks than mastery in testing and exams (Abu-Hilal, 2008). In this study, limitations on homework findings attained by several researchers will be considered by taking into account the hierarchical nature of the data.

\section{Purpose}

The purpose of the present study is to investigate how homework (HW) variables relate to achievement in mathematics within the specific classroom in Arab countries. Finding the influential factors that impact achievement in mathematics within particular countries will add more insights and understanding of students' performance in large scale assessments and enhance cross-cultural comparisons. Almost, there is no crosscountry research compared all Arab countries participated on large scale empirical data on this topic. This study relies on the Trends in International Mathematics and Science Study (TIMSS) data collected in 2015 by the International Association for the Evaluation of Educational Achievement (IEA). The database enables us to examine 
different factors related to achievement across all countries, among those Arab countries.

For each country, variables at both student and class/teacher levels will be used to model the country's specific findings associated with homework and mathematics achievement. This study is focused to investigate the following research questions:

The first question concerns with the characteristics of time spent on doing homework (HW time), homework frequency (HW frequency), and achievement in mathematics for Arab countries under investigation.

RQ1: How achievement in mathematics differs according to HW time and HW frequency within Arab countries?

We expected to see changes in achievement according to HW time and HW in each Arab country.

The second research question will start addressing the levelling effect by including both the HW time and the HW frequency relationships with achievement in mathematics within Arab countries based on student and teacher levels.

RQ 2. Do HW time and HW frequency at student and teacher levels impact achievement in mathematics in each Arab country?

The third research question will focus on the control variables in the two levels.

RQ 3. Do HW time, HW frequency, computer use, and internet use at student level and student gender at classroom level impact achievement in mathematics in each Arab country?

\section{Significance of the study}

This research focuses on the analysis of the link between the HW time and HW frequency with achievement in mathematics. Exploring the relationships between such factors is considered important to Arab countries and facilitates comparisons with other countries using TIMSS database. Arab countries participation in TIMSS are less frequently included in international research that includes mostly high performing and developed countries. This study adds more information to research on HW and mathematics achievement within Arab countries. Also, the significance of the study comes through looking into different factors of homework that contribute to high achievement in mathematics for grade 8 students. In addition, to understand the practices of other countries could enhance the instruction in one's country. Comparisons across Arab countries participated in TIMSS 2015 help to find what accounts for achievement in each country. The next section will describe the data used in the analysis, followed by sample, instruments, definition of variables, and statistical analysis procedure.

\section{METHOD}

\section{Data}

The current study analyzed data obtained from TIMSS 2015, the sixth cycle of the IEA studies. TIMSS has been conducted every four years since 1995 at grade four and grade 
eight to measure mathematics and science achievement. Students from 57 countries in grade four and 47 countries in grade eight participated in this cycle 2015. To achieve the study goals and facilitate comparisons between selected countries in this investigation, responses of eighth-grade mathematics from 10 Arab countries were obtained from TIMSS database. Specifically, two data sets were retrieved from TIMSS website (https://timssandpirls.bc.edu/timss2015/international-database), student background and mathematics teacher background.

\section{Sample}

The sample of the current study includes 477 schools and 73,987 eighth grade students from 10 Arab countries. Students were drawn randomly using a two-stage stratified cluster sampling design from public and private schools to represent the target population in each country. The population is defined as "all students in their eighth year of formal schooling" (LaRoche, Joncas, \& Foy, 2016, p.3). To ensure participation rates and obtain unbiased estimates of parameters; population, school, and student standardized weights were constructed by TIMSS to facilitate analysis and report the results. All analyses were based on TIMSS's HOUWGT weighting variable.

\section{Instruments}

Mathematics achievement. The overall score for each student in mathematics is generated based on item response theory and reported using five plausible values. Achievement in mathematics is considered the dependent variable and homework variables are the independent variables.

\section{Student level;}

HW time is measured by one question in the student's background survey "BSBM25BA inquired: How long does it usually take you to finish your mathematics homework?" Response categories were as no mathematics homework (coded 1) ; 1-15 minutes (coded2); 16-30 minutes (coded 3); 31-60 minutes (coded 4); 61-90 minutes (coded 5); More than 90 minute (coded 6); Logically not applicable (coded 96); and Omitted or invalid (coded 99).

$H W$ frequency "BSBM25AA inquired: How often does your teacher give you homework in mathematics? "' Response categories were as every day (coded 5); 3-4 times a week (coded 4); 1-2 times a week (coded 3); Less than once a week (coded 2); Never (coded 1); and Omitted or invalid (coded 9).

Computer use is a student level variable inquires employing computers to do HW. It is measured by BSBG13A "How often do you use a computer or tablet at home for schoolwork including homework?" responses were as4: everyday, 3: Once a week, 2: Once or twice a month, 1: Never or almost never, 9: Omitted or invalid.

Internet use to access assignment is a student level variable inquires employing internet at home to do tasks is measured one question "BSBG14B: Do you use the Internet to access the assignment posted online by teacher?" Reponses were: 1: Yes, 0: No, 9: Omitted or invalid".

Internet use to collaborate with classmates is a student level variable inquires collaboration with others while doing homework via internet is measured by one 
question "BSBG14C: Do you use the Internet to collaborate with classmates on assignment?" Responses were as 1: Yes, 0: No, 9: Omitted or invalid.

Internet use to find information is a student level variable inquires finding extra information to assist understanding is measured by one question "BSBG14E: Do you use the Internet to find information to aid understanding math?" Responses were as 1: Yes, 0: No, 9: Omitted or invalid.

Class level;

$H W$ Avg. time is measured by one question in mathematics teacher's survey "BTBM22B: When you assign mathematics homework to students in this class, about how many minutes do you usually assign?" Responses were as 1: <=15 min.; 2: 16-30 min.; 3: 61-60 min.; 4: 61-90 min.; 5: > $90 \mathrm{~min}$; 6: not applicable; and 9: Omitted or invalid.

$H W$ frequency is measured by "BTBM22A: How often do you assign mathematics homework to students in this class?" response categories were as 1: No Math HW, 2: < once a week, 3: 1-2 times a week, 4: 3-4 times a week, 5: everyday, 9: Omitted or invalid.

Student gender is a class level variable because boys and girls are located separately in single sex classrooms. Reponses were coded as 0: Female, 1: Male, 9: Omitted or invalid.

\section{Variables}

The main goal of the current analysis of TIMSS 2015 data is to examine the relationship between homework variables and performance in mathematics controlling for student and class level data.

Level 1, student variables are HW time, HW frequency, computer use, and internet use.

Level 2, teacher variables are HW frequency, HW Avg. time, and gender.

HW time at the student level is an indicator of the working speed in which the student complete a homework, whereas the HW Avg. time at the class level is a measure of typical assignment length given by the teacher. The class HW Avg. time may predict mathematics achievement more and above the effect of student time typically spent on homework.

HW frequency at the student level is an indicator of HWs he/she takes, whereas the HW frequency at the class level is a measure of typical number of HW occasions assigned by the teacher.

\section{Statistical analysis}

A multi-group two-level modeling procedure in Mplus 8.0 (Muthén \& Muthén, 19982017) was used to estimate the amount of variance in achievement that can be explained by hierarchically structured data, student's level and teacher's level. This procedure allows us modeling the achievement at both levels and examining the changes in estimates of variance components after adding level variables. 
In this study, much of the interest is on variability within and between classes across groups using one data set, countries as the grouping variable. Several models adding successively layer of variables were tested for each country to model achievement in mathematics of grade 8 students.

The first model was a "null" variance component that fitted a variance-component with no predictors.

The second model examined the students' level variables: HW time and HW frequency with achievement in mathematics after controlling the teachers' level variables: HW frequency, HW Avg. time.

The third model contained a group of student variables including HW time, HW frequency, computer use, and internet use questions in addition to classroom variables, that is, the teacher variables related HW frequency, and HW Avg. time.

The fourth model examined if the student's gender as a class level variable mediates the relationships between independent variables and achievement in mathematics. Our hypothesis is that both HW time and HW frequency significantly correlate with mathematics achievement in different ways at student and class levels after controlling for student gender.

Grouping command in MPLUS facilitates analysis and applying the same sequence of models for each country. To maximize interpretability, within-level variables were centered and standardized around their group mean (Cohen, Cohen, West \& Aiken, 2003, p. 564). As a result, regression coefficients represent the change in achievement scores due to an increase by one standard deviation above the standardized mean of the relevant variable.

\section{FINDINGS}

In homework context, investigating the association between time, frequency, and related factors with performance in mathematics was considered important at Arab countries using TIMSS database. To answer RQ1, table 1 divides students' responses in each country according to HW time and HW frequency.

Table 1

Preliminary analysis of student percents according to HW frequency and average scores in mathematics

\begin{tabular}{llllllll}
\hline Country & Valid N & $\begin{array}{c}\text { Every } \\
\text { day } \%\end{array}$ & $\begin{array}{c}3-4 \\
\text { times a } \\
\text { week } \%\end{array}$ & $\begin{array}{c}1-2 \\
\text { times } \\
\text { a week } \%\end{array}$ & $\begin{array}{c}\text { <once a } \\
\text { week \% }\end{array}$ & $\begin{array}{c}\text { Never } \\
\%\end{array}$ & $\begin{array}{c}\text { Omitted } \\
\%\end{array}$ \\
\hline Bahrain & 4691 & 35.8 & 27.9 & 19.3 & 11.1 & 6.0 & 4.4 \\
& & $(445.5)$ & $(456.4)$ & $(471.2)$ & $(469.8)$ & $(438.3)$ & $(414.7)$ \\
Egypt & \multirow{2}{*}{7424} & 40.6 & 30.9 & 18.0 & 3.9 & 6.6 & 5.2 \\
& & $(383.8)$ & $(403.5)$ & $(409.1)$ & $(412.4)$ & $(392.6)$ & $(320.7)$ \\
Jordan & 7616 & 46.7 & 36.9 & 10.7 & 3.4 & 2.2 & 3.3 \\
& & $(381.1)$ & $(395.9)$ & $(396.4)$ & $(399.4)$ & $(360.9)$ & $(305.1)$ \\
\hline
\end{tabular}

(Continued) 
Table 1 (Continued)

\begin{tabular}{llllllll}
\hline Country & Valid N & $\begin{array}{l}\text { Every } \\
\text { day } \%\end{array}$ & $\begin{array}{c}3-4 \\
\text { times a } \\
\text { week } \%\end{array}$ & $\begin{array}{c}1-2 \\
\text { times } \\
\text { a week } \%\end{array}$ & $\begin{array}{c}\text { <once a } \\
\text { week } \%\end{array}$ & $\begin{array}{c}\text { Never } \\
\%\end{array}$ & $\begin{array}{c}\text { Omitted } \\
\%\end{array}$ \\
\hline Kuwait & 4049 & 26.9 & 24.0 & 22.2 & 14.9 & 12.0 & 10.1 \\
& & $(406.9)$ & $(392.4)$ & $(390.0)$ & $(389.9)$ & $(374.7)$ & $(385.3)$ \\
Lebanon & \multirow{2}{*}{3578} & 67.7 & 21.7 & 5.9 & 2.8 & 1.9 & 8.6 \\
& & $(442.2)$ & $(455.1)$ & $(439.3)$ & $(446.6)$ & $(419.9)$ & $(419.8)$ \\
Morocco & \multirow{2}{*}{11896} & 46.2 & 36.8 & 9.7 & 4.7 & 2.7 & 8.6 \\
& & $(384.0)$ & $(389.9)$ & $(389.5)$ & $(386.2)$ & $(379.4)$ & $(359.9)$ \\
Oman & \multirow{2}{*}{8494} & 44.4 & 34.9 & 13.5 & 5.0 & 2.1 & 4.0 \\
& & $(400.5)$ & $(409.5)$ & $(411.7)$ & $(409.1)$ & $(377.3)$ & $(356.2)$ \\
Qatar & \multirow{2}{*}{5244} & 37.5 & 34.2 & 19.6 & 5.7 & 2.9 & 2.6 \\
& & $(425.4)$ & $(447.3)$ & $(460.4)$ & $(424.1)$ & $(403.2)$ & $(365.6)$ \\
Saudi Arabia & \multirow{2}{*}{3576} & 56.1 & 24.8 & 10.4 & 5.0 & 3.8 & 4.8 \\
& & $(362.5)$ & $(378.6)$ & $(383.6)$ & $(374.2)$ & $(359.3)$ & $(340.0)$ \\
United Arab & \multirow{2}{*}{17419} & 38.3 & 30.4 & 19.6 & 7.9 & 3.7 & 2.8 \\
Emirates & & $(459.6)$ & $(469.1)$ & $(478.6)$ & $(472.5)$ & $(433.5)$ & $(412.8)$ \\
International & 244326 & 39.6 & 28.4 & 19.2 & 8.4 & 4.3 & 3.1 \\
Avg. (39 & & $(479.7)$ & $(485.4)$ & $(479.0)$ & $(469.3)$ & $(438.4)$ & $(431.4)$ \\
countries) & & & & & & & \\
\hline
\end{tabular}

( ): Math Avg. represents averages of mathematics scores.

The analysis reported in table 1 shows that the highest scores in mathematics were obtained by Bahraini students. Approximately $60 \%$ of them work on assignment homeworks at least 3 to 4 times a week. From preliminary analysis, it is concluded that a small number of students in all Arab countries reported a lack of taking homework in mathematics (less than once a week or Never) except for Kuwait, where the number of students who reported a lack taking homeworks (26.9\%) equals the number of students who took homework every day.

Lebanese and Moroccan students have the highest average in mathematics when teacher assigns homework 3 or 4 times a week matching the international average. Students from GCC countries except Kuwait have the highest average in mathematics when teachers assign less frequent homework approximately 1 or 2 times a week. Jordanian and Egyptian students have similar situation, they were assigned less frequent homeworks, less than once a week, when achieved their highest average in mathematics. At the opposite side, Kuwaiti students achieved the highest average in mathematics when assigned homework every day.

The conclusion from table 1 would be that, in all Arab countries except Egypt, students would not need to have homework every day to strengthen and deepen knowledge and skills in mathematics. Generally, from 1 to 4 times would be enough to reach the highest average in mathematics. On the same direction, students with no homework are more likely to achieve the least average in mathematics. 
Table 2

Student percents according to the number of minutes spent on homework and average scores in mathematics across Arab countries

\begin{tabular}{|c|c|c|c|c|c|c|c|c|}
\hline Country & Valid N & $\begin{array}{l}\text { No math. } \\
\text { HW\% }\end{array}$ & $\begin{array}{l}1-15 \\
\min . \%\end{array}$ & $\begin{array}{l}16-30 \\
\min . \%\end{array}$ & $\begin{array}{l}31-60 \mathrm{~min} . \\
\%\end{array}$ & $\begin{array}{l}61-90 \\
\min . \%\end{array}$ & $\begin{array}{l}>90 \\
\min . \%\end{array}$ & Omit $\%$ \\
\hline \multirow{2}{*}{ Bahrain } & 4672 & 6.8 & 48.7 & 25.1 & 8.1 & 2.0 & 3.3 & 10.9 \\
\hline & & (406.2) & (465.6) & (459.7) & (457.1) & (454.5) & (416.7) & (428.1) \\
\hline \multirow{2}{*}{ Egypt } & & 15.1 & 37.7 & 22.2 & 9.2 & 2.7 & 6.3 & 13.1 \\
\hline & 7336 & (343.5) & $(414.1)$ & (412.3) & (405.0) & (380.0) & (365.1) & (359.8) \\
\hline \multirow{2}{*}{ Jordan } & & 7.7 & 46.7 & 29.3 & 8.4 & 2.0 & 3.9 & 6.0 \\
\hline & 76581 & (315.8) & (402.6) & (399.0) & (385.2) & (340.3) & (336.6) & (328.6) \\
\hline \multirow{2}{*}{ Kuwait } & & 6.3 & 48.5 & 22.7 & 6.5 & 1.2 & 2.8 & 22.1 \\
\hline & 4051 & (342.0) & (403.0) & (406.2) & (385.6) & (371.9) & (344.4) & $(379.2)$ \\
\hline \multirow{2}{*}{ Lebanon } & & 10.0 & 38.5 & 31.3 & 12.6 & 4.3 & 1.3 & 11.8 \\
\hline & 3530 & (406.1) & (451.8) & (456.2) & (439.3) & (430.4) & (411.7) & (419.6) \\
\hline \multirow{2}{*}{ Morocco } & & 12.2 & 39.5 & 25.9 & 12.1 & 2.9 & 4.7 & 13.3 \\
\hline & 11658 & (345.3) & (395.8) & (397.0) & (392.5) & (380.4) & (366.1) & (364.0) \\
\hline \multirow{2}{*}{ Oman } & & 10.5 & 60.7 & 18.4 & 4.6 & 1.5 & 2.2 & 5.1 \\
\hline & 8495 & (358.2) & (418.4) & (403.8) & (396.5) & $(365.0)$ & (364.5) & (359.8) \\
\hline \multirow{2}{*}{ Qatar } & & 6.3 & 40.1 & 28.7 & 15.7 & 3.8 & 2.6 & 5.6 \\
\hline & 5242 & (361.7) & (427.9) & (455.7) & (476.7) & (458.3) & (396.4) & (386.2) \\
\hline \multirow{2}{*}{ Saudi Arabia } & & 8.9 & 59.5 & 18.3 & 4.4 & 1.6 & 3.5 & 9.5 \\
\hline & 3550 & (313.6) & (381.0) & (382.4) & (351.8) & (330.8) & (310.3) & (343.1) \\
\hline \multirow{2}{*}{$\begin{array}{l}\text { United Arab } \\
\text { Emirates }\end{array}$} & & 5.0 & 40.8 & 29.9 & 14.1 & 3.1 & 3.4 & 6.6 \\
\hline & 17364 & (379.3) & (460.5) & (482.9) & (496.7) & (476.2) & (419.6) & (424.8) \\
\hline International & & 3.8 & 29.5 & 32.6 & 20.6 & 5.1 & 4.0 & 8.0 \\
\hline $\begin{array}{l}\text { Avg. ( } 39 \\
\text { countries) }\end{array}$ & 243097 & (409.5) & (478.7 & (490.6) & $(490.5)$ & (482.8) & (456.5) & (435.8) \\
\hline
\end{tabular}

( ): Math Avg. represents averages of mathematics scores.

Findings from table 2 show that the majority of Arab students spend less time doing homework (less than 60 minutes). Countries of Bahrain, Egypt, Jordan, and Oman showed the great benefits on achievement when spending less time doing homework. Countries of Kuwait, Lebanon, Morocco, and Saudi Arabia got the great benefit when spending 16-30 minutes doing homework. Surprisingly, students in two countries differ from that, Qatar and United Arab Emirates, achieved the highest benefit when doing longer homeworks (31-60 minutes).

Generally, it can be noted that students in countries of Lebanon and Saudi Arabia prefer short and frequent homeworks; meanwhile, students from Bahrain, Jordan, Oman, Qatar, and United Arab Emirates prefer short homeworks every day or at least 3 to 4 times a week. Kuwaiti students prefer short and less frequent homeworks.

Two-level model analysis.

Four models of two-level analysis that associate homework with achievement in mathematics were performed. One common way of starting the multi-level analysis is to examine a so-called null model that contains no predictors. Model 1 is the baseline 
model for comparisons with more advanced models. The intraclass correlation (ICC) indicates that $77.7 \%$ to $92 \%$ of the variance in mathematics scores are found in level 1 (within students), and $8.0 \%$ to $22.3 \%$ of the variance are found in level 2 (between teachers). Table 3 reports results of the second model that include the HW frequency and HW time variables.

Student-level model: $Y_{i j}=\pi_{0 j}+e i j$,

Teacher-level model: $\pi_{0 j}=\beta_{00}+u_{j}$

Where $Y_{\mathrm{ij}}$ is the mathematics achievement of student $\mathrm{i}$ within teacher ${ }_{\mathrm{j}} ; \pi_{0 j}$ is the mean achievement of class ${ }_{j}$, and $e_{i j}$ is student effect or residual (deviation of student $i$ from the respective teacher mean). $\beta_{00}$ is the mean achievement in class, and $u_{j}$ is class effect or residual.

Table 3

Multiple group analysis, the null model to predict achievement in mathematics with no predictors

\begin{tabular}{|c|c|c|c|c|c|c|}
\hline Source & $\begin{array}{l}\text { Within- } \\
\text { student level }\end{array}$ & $\begin{array}{l}\text { Residual variance } \\
\text { / BSMMAT }\end{array}$ & $\begin{array}{l}\text { Between- } \\
\text { teacher level }\end{array}$ & Intercept & $\begin{array}{l}\text { Residual variance / } \\
\text { BSMMAT }\end{array}$ & $\begin{array}{l}\text { Intra-class } \\
\text { correlation }\end{array}$ \\
\hline Bahrain & & $4538.327^{* * * *}$ & & 461.486 **** & $2432.593^{* * * *}$ & 0.159 \\
\hline Jordan & & 6500.467 **** & & $382.263^{* * * *}$ & $1983.234 * * * *$ & 0.162 \\
\hline Kuwait & & $4860.942 * * * *$ & & $382.733^{* * * *}$ & $2470.339^{* * * * *}$ & 0.134 \\
\hline Lebanon & & $3430.050^{* * * *}$ & & $444.740 * * * *$ & $2053.145^{* * * * *}$ & 0.178 \\
\hline Morocco & & $4892.284 * * *$ & & $385.572 * * *$ & $1341.899 * * *$ & 0.223 \\
\hline Oman & & $7240.893^{* * * *}$ & & $401.565^{* * * *}$ & $2481.990^{* * * *}$ & 0.139 \\
\hline Qatar & & $5472.475^{* * * *}$ & & $444.964 * * * *$ & $5134.063^{* * * *}$ & 0.08 \\
\hline Saudi Arabia & & $5047.482^{* * * * *}$ & & $370.756 * * *$ & $1969.133^{* * * * *}$ & 0.158 \\
\hline $\begin{array}{l}\text { United Arab } \\
\text { Emirates }\end{array}$ & & $4566.161 * * *$ & & $461.199 * * *$ & $4815.733^{* * * *}$ & 0.087 \\
\hline Egypt & & $6477.283^{* * * *}$ & & $403.264 * * *$ & $3454.384^{* * * * *}$ & 0.105 \\
\hline
\end{tabular}

$* * * \mathrm{p}<.001$

Model 1 results shown in table 3 explain that only $23 \%$ of the variance of mathematics achievement was between classes relative to $92 \%$ was within classes.

Table 4

Multiple group analysis of a two-level modelling conducted to associate HW frequency and HW time with achievement in mathematics.

\begin{tabular}{|c|c|c|c|c|c|c|c|}
\hline \multirow[b]{2}{*}{ Source } & \multicolumn{3}{|c|}{ Within-student level } & \multicolumn{4}{|c|}{ Between-teacher level } \\
\hline & $\begin{array}{l}\text { HW freq. I } \\
\text { BSBM25AA }\end{array}$ & $\begin{array}{l}\text { HW time / } \\
\text { BSBM25BA }\end{array}$ & $\begin{array}{c}\text { Residual } \\
\text { variance / } \\
\text { BSMMAT }\end{array}$ & $\begin{array}{l}\text { HW freq. I } \\
\text { BTBM22A }\end{array}$ & $\begin{array}{l}\text { HW time / } \\
\text { BTBM22B }\end{array}$ & Intercept & $\begin{array}{c}\text { Residual } \\
\text { variance / } \\
\text { BSMMAT }\end{array}$ \\
\hline Bahrain & $-6.883 * * *$ & $-6.207 * * *$ & $4489.729 * * *$ & -8.886 & $16.595^{* * *}$ & $470.387^{* * * *}$ & 2306.231 **** \\
\hline Jordan & $-9.061 * * *$ & $-3.610^{* *}$ & $6357.108^{* * * * *}$ & 4.644 & 0.214 & $365.555^{* * * *}$ & $1873.161^{* * * *}$ \\
\hline Kuwait & $-6.729 * *$ & $-10.212 * * *$ & $4842.639^{* * * *}$ & $9.878^{*}$ & 10.668 & $338.292 * * *$ & $2499.136^{* * * * *}$ \\
\hline Lebanon & -1.308 & -1.619 & $3398.382^{* * * *}$ & $10.295^{*}$ & 0.972 & $487.251^{* * *}$ & $2013.420^{* * * *}$ \\
\hline Morocco & -2.196 & 0.296 & $5037.243 * * *$ & -0.389 & 2.815 & $384.311 * * *$ & $1207.620^{* * * * *}$ \\
\hline Oman & $-11.263 * * *$ & $-5.327^{* * * *}$ & $7017.115^{* * * * *}$ & $7.900^{*}$ & 5.561 & $361.517^{* * * *}$ & $2153.722^{* * * * *}$ \\
\hline Qatar & $-5.862^{* * *}$ & -2.57 & $5444.816^{* * * * *}$ & 4.514 & $36.729^{* * * *}$ & $353.527^{* * *}$ & $3988.833^{* * * *}$ \\
\hline Saudi Arabia & $-12.222^{* * * *}$ & $-7.010^{* * *}$ & $5167.333^{* * * *}$ & 0.45 & 13.138 & $350.474 * * *$ & $1985.992 * * * *$ \\
\hline \multicolumn{8}{|c|}{ United Arab } \\
\hline Emirates & $-6.950 * * *$ & $-3.429 * * *$ & $4513.669^{* * * *}$ & -0.984 & $25.790 * * *$ & $418.049^{* * * *}$ & $4358.583^{* * * *}$ \\
\hline Egypt & $-10.849 * * *$ & 0.239 & $6428.982 * * * *$ & 2.974 & $12.168^{*}$ & $370.071^{* * * *}$ & $3354.897 * * *$ \\
\hline
\end{tabular}

Note: $B$ : is unstandardized regression coefficient; $\mathrm{R}=$ Recoded; All within-level variables are group-mean centered.

$* \mathrm{p}<.05, * * \mathrm{p}<.01, * * * \mathrm{p}<.001$ 
To answer RQ2, model 2 was created and specified in the subsequent step. This step controls the differences in achievement levels after HW time and HW frequency were included as predictors at student and class levels. As reported in Table 4, HW frequency had a significant negative effect at the student level in eight Arab countries and a significant positive effect at the classroom level in four Arab countries. Meanwhile, HW time had a significant negative effect at the student level in six Arab countries and a significant positive effect at the classroom level in four Arab countries. In other words, individual students who spent more time on homework and took more frequent homeworks than their colleagues scored lower on mathematics, whereas a high average of HW time and HW frequency at the class level was positively related to achievement. HW time explained $0.35 \%$ to $20.76 \%$ of the variance at level 2 and $0.18 \%$ to $6.17 \%$ at level 1 . However, because other predictor variables, such as gender, were not controlled in Model 2, the homework achievement relationship identified might still be questionable.

Table 5

Multiple group analysis of a two-level modeling

\begin{tabular}{|c|c|c|c|c|c|c|c|c|c|c|}
\hline Source & $\mathrm{BAH}$ & JOR & KUW & LEB & MOR & OMA & QAT & SAU & UAE & EGY \\
\hline \multicolumn{11}{|c|}{ Within-student level } \\
\hline $\begin{array}{l}\text { HW freq. I } \\
\text { BSBM25AA [R] }\end{array}$ & $-6.754 * * *$ & $-7.785^{* * * *}$ & 4.278 & -1.178 & -1.871 & $-11.910 * * *$ & $-5.563^{* * *}$ & $-11.411 * * *$ & $-6.736 * * *$ & $-10.855^{* * *}$ \\
\hline $\begin{array}{l}\text { HW time / } \\
\text { BSBM25BA }\end{array}$ & $-6.422 * * *$ & $-4.535 * * *$ & -9.343 & -1.843 & -0.339 & $-5.067 * * *$ & -2.064 & $-7.518^{* * *}$ & $-3.454 * * *$ & 0.001 \\
\hline $\begin{array}{l}\text { PC use at home / } \\
\text { BSBG13A [R] }\end{array}$ & -2.730 & $3.186^{*}$ & -0.582 & -1.885 & -1.341 & $5.218 * * *$ & -0.669 & -0.876 & $4.473 * * *$ & $-3.942 * *$ \\
\hline $\begin{array}{l}\text { Computer use at } \\
\text { home to do task } \\
\text { / BSBG14B [R] }\end{array}$ & -4.189 & -1.948 & -10.839 & -4.376 & $4.923^{*}$ & -2.503 & $8.249 *$ & 4.602 & $7.996^{* * * *}$ & $-7.088^{*}$ \\
\hline $\begin{array}{l}\text { PC at home to } \\
\text { do task / } \\
\text { BSBG14C [R] }\end{array}$ & -0.761 & -4.878 & -10.460 & 7.821 & 3.145 & -2.413 & $-7.572 * *$ & 5.734 & $-4.932 *$ & -5.029 \\
\hline $\begin{array}{l}\text { PC use at home } \\
\text { to do task / } \\
\text { BSBG14E [R] }\end{array}$ & 1.246 & $-9.768 * * *$ & 7.836 & -7.164 & -0.328 & 1.695 & $-9.891 * * *$ & 4.877 & $-6.418 * * *$ & 4.039 \\
\hline $\begin{array}{l}\text { Residual } \\
\text { variance / } \\
\text { BSMMAT }\end{array}$ & $4478.4 * * *$ & $6193.02 * * *$ & $4362.9 * * *$ & $3322.1 * * *$ & $4995.9 * * *$ & $6897.1^{* * * *}$ & $5322.9 * * * *$ & $5147.1 * * *$ & $4489.4 * * * *$ & $6256.9^{* * * *}$ \\
\hline \multicolumn{11}{|c|}{ Between-teacher level } \\
\hline $\begin{array}{l}\text { HW frequency / } \\
\text { BTBM22A }\end{array}$ & $-11.791 * *$ & 1.936 & -29.185 & $-1.122 *$ & -0.390 & 0.988 & 0.678 & -2.962 & -4.003 & 3.103 \\
\hline $\begin{array}{l}\text { HW time / } \\
\text { BTBM22B }\end{array}$ & $17.938 * *$ & -1.663 & 63.683 & 2.024 & 2.981 & 6.379 & $39.351 * * *$ & 11.209 & $25.976 * * *$ & $12.610^{*}$ \\
\hline $\begin{array}{l}\text { Gender } \\
\text { / BTBG02 [R] }\end{array}$ & $-23.752 * *$ & $-15.873 * *$ & 17.019 & 4.316 & -2.717 & $-28.423 * * * *$ & $-27.865 * *$ & -15.133 & $-16.321^{* *}$ & -8.887 \\
\hline Intercept & $491.8^{* * * *}$ & $390.3 * * *$ & $474.2^{* * *}$ & 487.2 **** & $388.6^{* * * *}$ & $405.1^{* * * * *}$ & $378.6 * * *$ & $375.4 * * *$ & $437.5^{* * * *}$ & 378.3 \\
\hline $\begin{array}{l}\text { Residual } \\
\text { variance } \\
\text { BSMMAT }\end{array}$ & $2083.8^{* * * *}$ & $1655.4 * * *$ & $3463.3 *$ & $1974.5^{* * *}$ & $1215.9^{* * * *}$ & $1893.4 * * *$ & $3815.4 * * *$ & $1967.5^{* * * *}$ & $4208.7^{* * * *}$ & 3257.5 \\
\hline
\end{tabular}

Note: $B$ : is unstandardized regression coefficient; $\mathrm{R}=$ Recoded; All within-level variables are group-mean centered. $* \mathrm{p}<.05, * * \mathrm{p}<.01, * * * \mathrm{p}<.001$

To answer the third research question, model 3 was created to examine HW time, HW frequency, Computer use, and Internet use at the level 1; and both HW time and HW frequency variables at the level 2. As shown in table 5, not all of these variables were statistically significantly related to mathematics achievement. With the United Arab students, all variables were significantly correlated with achievement in mathematics in the two levels, followed by Qatari students who reported non-significance of HW time 
and computer use at the student level and HW frequency at the class level. Different associations between predictors and achievement in mathematics were seen in most of Arab countries.

Similarly, at the student level, HW time and HW frequency were closely associated with achievement in different directions (positive or negative). The effect of gender was statistically significant (controlling for the other variables in the model), which means that females achieved better than males.

The effects of HW time and HW frequency were the particular interest in the present study. At the class level, when the additional predictors were included in Model 3, the size of the HW time and HW frequency effects decreased dramatically in almost all countries.

\section{DISCUSSION}

The current study was carried out to find the relationship between homework and achievement in mathematics using TIMSS database. Generally, it was found that longer homeworks (spending more than 60 minutes) could be seen as a source of annoyance for students. On the other side, shorter and less frequent homeworks (1 to 4 times a week) reflects an important source of improving achievement in most Arab countries. Correlations differed significantly between males and females, girls exceeding those for boys. These differences suggest that homework plays a more important role in the achievement scores of females than those of males. Although TIMSS dataset provides a unique opportunity to study the relationship between homework and achievement; it has some limitations in the current study. First, it is unfeasible to conclude the causal directions of the observed effects due to the cross-sectional design executed in TIMSS 2015. Second, variable set does not allow deep examination of the relationship between time and effort while doing homework, such variables together are important to our understanding of the homework styles.

From the study findings we cannot claim that low achieving students take more time doing their homework because their prior knowledge and skill are low; or might claim that longer homeworks could indicate difficulty in concentration that result in low achievement. Rønning (2010) considered longer time spent on doing homework can be an expression of high motivation rather than problems of understanding.

It is widely accepted among educators and students that homework is associated with improved performance, when the two-level modeling was used to separate student level and class level effects. The analyses somewhat confirmed that the relationship between homework variables and achievement is only moderate at the class level and is in fact negative at the student level. Teachers are recommended to increase homework frequency when they rely on homework to teach new concepts. In Latin America, Martinez-Garrid (2014) recommended that homework duration must not exceed half an hour a day in primary schools. In addition, his encourage is that teachers must incorporate homework in lessons and must use the accumulated knowledge and abilities during homework into teaching. 
Literature in homework (Kandemir \& Gür , 2009; Stefan, 2015) mentioned that the biggest need at this moment is enriching traditional methods of doing homework by introducing new modern methods that are capable to arouse students' interest, involve creativity and to develop critical thinking. Although homework can encourage students to be independent learners, it can have a negative effect on student's progress. Longer homework leads to boredom especially when it contains repetitive tasks. Also, homework can deny students to access leisure activities (Costley, 2013). Providing feedback is one of the important factors that increase the homework efficiency.

From the teacher's perspective, homework helps to condense the time secured for teaching the subject in the classroom. It helps the student to be independent and connects learning at home with learning at school.

Students reported that less time spent on doing homework and less frequent homeworks assigned by teachers are better and enhance achievement. One of the interpretations states that homeworks should be valued firstly by students and more weight should be given from teachers to the development of homework (Ekici, 2014).

\section{IMPLICATIONS AND CONCLUSION}

The analysis of homework relationships with achievement in Arab countries is important for education systems. The homework efficiency differs in some countries, e.g. Kuwait and Egypt. Everyday homework contributed to lower average achievement in mathematics. In other Arab countries, students achieved higher scores when assigned less frequent homeworks in mathematics. The result could be interpreted in terms of the consistency between instruction and homework evaluation.

Most of the teachers still use the traditional methods in teaching compared with modern teaching methods (Balliu \& Belshi, 2017). They have the central and the biggest place during the class time isolating homework from learning process. In this case, students would need more time doing homework. If teachers try to make learning easier during class time and encourage students to be active in learning, this would help students do their homeworks in lesser time and more efficiently. More importantly, homework would concentrate on applying knowledge and skills acquired during class time rather than learning.

One of the factors that may force teachers to use traditional methods in teaching is the crowded classrooms. Teacher will not have enough time and space for each student to have an active role during the class time. Therefore, majority of the activities that should take place during class are switched to be done at home. The time given to homework should not be spent on learning, a process that should be take place during class time. Instead, homework must involve challenges that develop creativity, critical thinking, and motivate student to be an efficient learner who seeks the increment in his performance.

\section{REFERENCES}

Abu-Hilal, M. (2008). Motivation, attribution of academic experiences and achievement among Arab students within a socio-cultural context. In T. O. Seng, D. M. McInerney, A. D. Liem, \& T. Ai-Girl (Eds.), Construct validity of self-concept in TIMSS's SBQ Research in 
multicultural education and international perspectives (Vol. 7, pp. 217-244). Greenwich: Information Age Publishing.

Bafile, C. (2005). Help for Homework Hassles, Vol 1. Education World. Retrieved 18 December, 2017 from http://www.educationworld.com/a_curr/homeworktips/homeworktips001.shtml

Baker, D. \& LeTendre, G. (2005). National differences, global similarities: World culture and the future of schooling. Stanford, CA: Stanford University Press.

Balliu, V. \& Belshi, M. (2017). Modern Teaching Versus Traditional Teaching- Albanian Teachers Between Challenges and Choices. European Journal of Multidisciplinary Studies, 4(4), 20-26. DOI: 10.26417/ejms.v4i4.p20-26

Carmichael, C. \& MacDonald, A. (2014) Parental influences on primary school children's mathematics achievement: insights from the Longitudinal Study of Australian Children. Education 3-13, 44/2, 197-211, DOI: 10.1080/03004279.2014.939684

Cheema, J. \& Sheridan, K. (2015). Time spent on homework, mathematics anxiety and mathematics achievement: Evidence from a US sample. Issues in Educational Research, 25/3, 246-259.

Cohen, J., Cohen, P., West, S., \& Aiken, L. (2003). Applied Multiple Regression/ Correlation: Analysis for the Behavioral Sciences, third Edition. New Jersey: Lawrence Erlbaum Associates, Inc., Publishers.

Cooper, H., Lindsay, J. \& Nye, B. (2000). Homework in the Home: How Student, Family, and Parenting-Style Differences Relate to the Homework Process. Contemporary Education Psychology, 25/4, 464-487. doi:10.1006/ceps.1999.1036

Cooper, H., Steenbergen-Hu, S., \& Dent, A. (2012). Homework. In K. R. Harris, S. Graham, \& T. Urdan (Eds.), APA educational psychology handbook, Vol. 3: Application to learning and teaching. (pp. 475-495) Washington, DC: American Psychological Association. http://dx.doi.org/10.1037/13275-019

Cooper, H., Robinson, J. , \& Patall, E. (2006). Does homework improve academic achievement? A synthesis of research, 1987-2003. Review of Educational Research, 76/1, 162.

Dawson, C. (2013). The impact of an online component in a face-to-face community college mathematics class (California State University, Stanislaus; Ed.D.).

Dettmers, S., Trautwein, U., \& Lüdtke, O. (2009). The relationship between homework time and achievement is not universal: Evidence from multilevel analyses in 40 countries. School Effectiveness and School Improvement, 20, 375-405. .http://dx.doi.org/10.1080/ 09243450902904601

Dodson, J. (2014). The impact of online homework on class productivity. Science Education International, 25/4, 354-371.

Ekici, F. (2014). Elementary school students' views on the homework given in science courses. Educational Research Reviews, 9/17, 594-605. 
Farrell, A. \& Danby, S. (2013). How does homework 'work' for young children? Children's accounts of homework in their everyday lives, British Journal of Sociology of Education, 36/2,250-269, DOI: 10.1080/01425692.2013.814532

Falch, T. \& Rønning, M. (2011). Homework assessment and student achievement in OECD countries. Department of Economics, Norwegian University of Science and Technology, Working Paper Series, 5, 1-33.

Hopkins, G. (2005). How Does Your School Handle the Homework Dilemma? Education $\begin{array}{lllll}\text { World. } & \text { Retrieved } & 5 & \text { January, } & 2018\end{array}$ http://www.educationworld.com/a_admin/admin/admin432.shtml.

Kandemir, M. \& Gür , H. (2009). The use of creative problem solving scenarios in mathematics education: views of some prospective teachers. Procedia Social and Behavioral Sciences, 1, 1628-1635.

Kitsantas, A., Cheema, J. \& Ware, H. (2011). Mathematics achievement: The role of homework and self-efficacy beliefs. Journal of Advanced Academics, 22/2, 310-339.

Horsley, M. \& Walker, R. (2013). Reforming Homework: Practices, Learning and Policies. Macmillan Education: UK.

Lamb, S. \& Fullarton, S. (2001). Classroom and school factors affecting mathematics achievement: A comparative study of the US and Australia using TIMSS. Paper presented at the Annual Conference of the American Educational Research Association, Seattle, Washington, April 10-14, 2001.

LaRoche, S., Joncas, M., \& Foy, P. (2016). Sample Design in TIMSS 2015. In M. O. Martin, I. V. S. Mullis, \& M. Hooper (Eds.), Methods and Procedures in TIMSS 2015 (pp. 3.1-3.37). Retrieved from http://timss.bc.edu/publications/timss/2015

Margolis, H. (2005). Resolving struggling learners' homework difficulties: Working with elementary school learners Parents. Preventing School Failure, 50/1, 5-13.

Murillo, F. \& Martinez-Garrido, C. (2014). Homework and primary-school students' academic achievement in Latin America. Int. Review of Education, 60/5, 661-681.

Muthén, L. K. \& Muthén,B. O. (1998-2017). Mplus user's guide ( $8^{\text {th }}$ ed.). Los Angelas, CA: Muthén \& Muthén.

Mau, W. \& Lynn, R. (2000). Gender differences in homework and test scores in mathematics, reading and science at tenth and twelfth grade. Psychology, Evolution \& Gender, 2/2, 119-125.

Mikk, J. (2006). Students' Homework and TIMSS 2003 Mathematics Results. Paper presented at the International Conference "Teaching Mathematics: Retrospective and Perspectives" (7th, Tartu, Estonia, May 12-13, 2006). ERIC Number: ED491866.

Phan H., Sentovich C., Kromrey J., Dedrick R., \& Ferron J. (2010). Correlates of mathematics achievement in developed and developing countries: An analysis of TIMSS 2003 eighth-grade Mathematics scores. Paper presented at the Annual Meeting of the American Educational Research Association, Denver, Colorado, 30 April - 4 May. 
Power, T., Dombrowski, S., Watkins, M., Mautone, J.,\& Eagle, J. (2007). Assessing children's homework performance: Development of multi-dimensional, multi-informant rating scales. Journal of School Psychology, 45, 333-348.

Reach, K. \& Cooper, H. (2004). Homework Hotlines: Recommendations for Successful Practice. Theory into Practice, 43/3, 234-241.

Riddell, A. (1997). Assessing designs for school effectiveness research and school improvement in developing countries. Comparative Education Review, 41/2, 178-204.

Rochelle, J., Feng, M., Murphy, R. \& Mason, C. (2016). Online Mathematics Homework Increases Student Achievement. AERA OPEN, 2/4, 1-12.

Rodriguez, M. (2004). The Role of Classroom Assessment in Student Performance on TIMSS. Applied Measurement in Education, 17/1, 1-24.

Rowell, L., \& Hong, E. (2002).The role of school counselors in homework intervention. Professional School Counseling, 5, 285-291.

Rønning, M. (2010). Homework and pupil achievement în Norway. Evidence from TIMSS. Statistics Norway. Retrieved 18 December, 2017 from https://www.ssb.no/a/publikasjoner/pdf/rapp_201001/rapp_201001.pdf

Rudman, N. (2014). A review of homework literature as a precursor to practitioner-led doctoral research in a primary school. Research in Education, 91/2, 12-31.

Salend, S., Duhaney, D., Anderson, D., \& Gottschalk, C. (2004). Using the Internet to Improve Homework Communication and Completion. Teaching Exceptional Children, 36/3, 64-73.

Schleicher, A. (2002). Monitoring Student Knowledge and Skills. In D. Shorrocks-Taylor \& E. W. Jenkins (Eds.), Learning from others, International Comparisons in Education (pp. 63-77). New York: Kluwer.

Son, j., Han, S., Kang, c., \& Kwon, O. (2016). A Comparative Analysis of the Relationship among Quality Instruction, Teacher Self-efficacy, Student Background, and Mathematics Achievement in South Korea and the United States. Eurasia Journal of Mathematics, Science \& Technology Education, 12/7, 1755-1779.

Spătărelu, E. (2017). Evidence on Homework Efficiency in TIMSS Mathematics Achievement. Journal Plus Education. 17/1, 60-70.

Trautwein, U. (2007). The homework achievement relation reconsidered: Differentiating homework time, homework frequency, and homework effort. Learning and Instruction, 17, 372-388.

Valle, A., Regueiro, B., Núñez, J., Rodríguez, S., Piñeiro, I., \& Rosário, P. (2016) Academic Goals, Student Homework Engagement, and Academic Achievement in Elementary School. Frontiers in Psychology, 7, 463.

Warton, P. (2011). Learning about responsibility: lessons from homework. British Journal of Educational Psychology, 67/2, 213-221.

Wiseman, A., Abdelfattah, F., \& Almassaad, A. (2016).The Intersection of Citizenship Status, STEM. Education, and Expected Labor Market. Participation in Gulf Cooperation Council Countries. Digest of Middle East Studies, 25/2, 362-392. 